\title{
Rights-Based Approach to Human Development: Access to Health Care in Blouberg Municipality, South Africa
}

\author{
Chuene W. Rammutla \\ University of Limpopo, Tufloop Graduate School of Leadership \\ Webster Street, Edupark, Fauna Park, PO Box 759 , \\ Polokwane 0787, Republic of South Africa \\ Oliver Mtapuri \\ University of Limpopo, Tufloop Graduate School of Leadership \\ Webster Street, Edupark, Fauna Park, PO Box 759, \\ Polokwane 0787, Republic of South Africa \\ Email address: simbaomtapuri@yahoo.com
}

\section{Doi:10.5901/mjss.2014.v5n8p520}

\begin{abstract}
South Africa subscribes to universal health care coverage. Health care access has four dimensions: geographic accessibility, availability, financial accessibility and acceptability. Human rights instruments guarantee the right of everyone to health care access. However, the existence of such a right is not necessarily a proof of their actual enjoyment by those who are entitled to them. This study assessed these dimensions. The study used a quantitative approach in which a questionnaire was used. The health care centre is not within a $25 \mathrm{~km}$ radius of some of the consumers of health care while the roads are in poor condition, the community cannot afford transport fares. Travelling distance and time; and scarce skills and lack of medication and equipment constitute the demand-side and supply-side barriers respectively to health care access. As such health care users have resorted to using the services of churches and traditional healers. This study recommends a new model of delivery of health that Government should co-ordinate primary health care services in collaboration with churches and traditional healers; commission research into traditional health medicine and healing procedures and protocols of other health care providers; develop policy on cross-referral of patients; improve community participation; set minimum norms and standards for the delivery of alternative health care services; establish health care management guidelines for churches and traditional healers in order to provide health care in an integrated manner.
\end{abstract}

\section{Introduction}

The World Health Organisation (WHO) member-states endorsed the concept of universal coverage as early as 2005 (Currin et al 2008; Jacobs et al., 2011). According to this concept, the WHO member-states must provide health services on a non-discriminatory and integrated basis. While it does not discount the importance of curative health care, the concept of universal coverage nuances the strategic role of primary health care in the public health care delivery system (Nadasen, 2000). South Africa is a WHO member-state and, therefore, subscribes to the concept of universal coverage.

Section 27 of the South African Constitution provides that everyone has the right to have access to health services. The right to health care access is a universal, indivisible and integrated fundamental human right. The South African constitution enumerates the right to have access to, among others, food, water, sanitation, shelter and social security is listed together with, or penultimate, the right to health care access. Sachs J, in Soobramoney v Minister of Health, KwaZulu-Natal 1997 (12) BCLR 1696 (CC), stated that 'healthy life depends upon social interdependence: the equality of air, water, and sanitation which the state maintains for public good; the quality of one's caring relationships, which are highly correlated to health, as well as the quality of health care and support furnished officially by medical institutions and provided informally by family, friends and the community ...' According to Yacoob J, in the Government of the Republic of South Africa v Grootboom and Others 2000 (11) BCLR 1169 (CC) human rights are indivisible and mutually supportive. However, the existence of a right is not necessarily a proof of its actual enjoyment by those who are entitled to it. This article investigates whether people actually have health care access at RCHC. The article analyses the barriers that impede access to health care and proposes policy measures necessary to optimise universal coverage. 


\section{Literature Review}

\subsection{Human rights and health care access}

Human rights are referred to, interchangeably, as, among others, fundamental rights, basic rights, natural rights, subjective rights and sometimes even common rights (Mubangisi, 2004). The UNDP User Guide (UNDP, 2006) categorises fundamental rights into civil and political rights, social, cultural and economic rights and rights to healthy environment and development (see also Mubangisi, 2004). Olowu (2009) submits that economic, social and cultural rights are not hierarchically below civil and political rights.

The UNDP enjoins UN member-states to integrate human rights into development programs (UNDP, 2006). Article 25 of the Universal Declaration of Human Rights (UDHR) integrates health care, food, clothing, housing and social security. According to article 12 of the ICESCR a person is entitled to the 'enjoyment of the highest attainable standard of physical and mental health conducive to living a life of dignity'. The constitution of the WHO provides that health is a 'state of complete physical, mental and social well-being and not just the absence of disease or infirmity'. According to the General comment No 14 of the CESCR, health care is 'fundamental to the physical and mental well-being of all individuals and as a necessary condition for the exercise of other human rights'. The Vienna Declaration and Plan of Action provides that human rights and fundamental freedoms are universal, indivisible and interrelated birthright of all human beings (A/CONE 157/23(12 July 1993)). Article 16 of the African Charter on Human and Peoples' Rights guarantees the right to enjoy the best attainable state of physical and mental health, while article 24 guarantees the right to a general satisfactory environment favourable to their development. Section 27 of the South African Constitution integrates health care food, water, housing and social security. The right to health care of a person must be construed against the competing rights of others to health care and all other socio-economic rights which compete for the limited resources (Soobramoney v Minister of Health, KwaZulu-Natal 1997 (12) BCLR 1696 (CC); B v Minister of Correctional Services 19976 BCLR 789 (C); AZAPO v President of the RSA 19968 BCLR 1015 (CC)).

There is an interconnection between human rights and the basic social conditions in which people live (Currie and de Waal, 2005). In other words, basic social conditions affect human rights negatively or positively depending which way the pendulum turns. If the basic social conditions were bad the rights of people who live in them may be violated and if the converse were the case, the rights may be fulfilled. The interconnection of human rights and the basic social conditions led to the inclusion in the modern constitutions of the socio-economic or second-generation rights (Currie and de Waal, 2005). Cheadle et al. (2002) submit, in our view, correctly that -

[t]here is an obvious link between the right of access to health-care services, sufficiency in food and water and access to social security. Social security provides access to health, food and water which are essential for life.

The notion of public health includes access to water and sanitation, food, clothing, housing [and related needs] (Cheadle et al., 2002). According to Nadasen (2000), the right to health-care services does not guarantee the right to be healthy. Olowu (2009: 1) states that by their very nature socio-economic and cultural rights are designed to satisfy the conditions of poverty and deprivation. The UNDP human developments reports consistently reflect bad poverty and deprivation levels in African countries (UNDP 2007-2008). Life expectancy in Sub-Saharan Africa has declined to 49.6 years (UNDP 2007-2008).

\subsection{Alternative health services}

These are the services provided to the community by either the churches or traditional African religion. The alternative health care services complement public health-care services. In his Master of Theology degree dissertation (UNISA) (2004), Matsepe conducted a research into the provision of health care services among the African communities by African Initiated Churches. According to Mbiti (1969) religion and traditional health care practice play a significant role in the life, health and death of an African.

\subsection{Access to health care}

According to Oliver \& Mossialos (2004), there is no universally accepted definition of health care access. Peters et al (2008: 161-171) define health care access as 'the timely use of service according to need'. People in poor countries have less access to health services than those in better-off countries. Within a country, the poor have less access to health 
services than the rich. According to Todaro and Smith (2009), the health care facilities in poor rural areas are underequipped and understaffed. According to the Executive Summary of the South African Human Rights Commission Report (2009:6) -

Access to health care services, especially for the poor, is severely constrained by expensive, inadequate or nonexistent transport, by serious shortages with regard to emergency transport, and by long waiting times at clinics and other health care service providers.

According to the General Comments No 14 of the CESCR, the right to health care is equal access, based on the principle of non-discrimination, to health care facilities, goods and services. Health care facilities, goods and services must be available in sufficient quantity; must be physically and economically accessible to everyone; must be culturally and ethically acceptable; and must be scientifically and medically appropriate and of good quality.

\subsection{The dimensions of health care access}

There are four dimensions of health care access: geographic accessibility, availability, financial accessibility and acceptability (Peters et al., 2008). Quality of care is a component of each dimension of health care access (Peters et al., 2008). Access to health care involves more than the presentation of a patient at the premises of a health care facility. According to Jacobs et al (2011), health care utilisation is used as an operational proxy for health care access.

The geographic accessibility alludes to the distance between the place of abode of a user (a pick-up point) and the health care facility. Peters et al (2008) define geographic accessibility as 'the physical distance or travel time from service delivery point to the user'. It takes into account the modes of transport and status of the roads (hard infrastructure) to and from the health care facility, travel distance and traveling time and access to communication system (Peters et al., 2008).

Peters et al (2008) correctly point out that geographic access is an important part of accessing health care in Low and Middle Income Countries. It is noteworthy that access to a health facility is not a sufficient proof of the actual health care access, utilisation and realised need. The provision and utilisation of health care must be consistent with all pertinent norms and standards. It is noteworthy that health care access consummates at the point where a patient receives medical treatment of the right quality on time.

According to Peters et al (2008), an inverse relationship between distance or travel time to health facilities and use of health services is an important barrier to access to health care. Good roads are necessary for both the demand side and supply side of access to health care. On the one hand, the health care users use roads to and from the health care facilities. On the other hand, the health care providers use roads to distribute drugs and other supplies to health care facilities, for timely referrals in emergencies, and for better supervision of health care workers (Peters, 2008).

Availability of health care alludes to, among others, the existence and reachability of the health care facility, its institutional capacity, the availability of health care workers, the right numbers and competencies of the workforce, the availability of medical instruments and equipment, the business hours, treatment of emergencies outside working hours, the length of waiting periods and the availability of the right quality and quantity of medication and drugs. According to Peters et al (2008:5), availability is measured in terms of the opportunity to have access to health care as and when needed. He defines availability as 'having the right type of care available to those who need it, such as hours of operation and waiting times that meet demands of those who would use care, as well as having the appropriate type of service providers and materials'.

\subsection{Financial accessibility of healthcare}

Health care is costly. The dimension of financial accessibility recognises that socio-economic rights are onerous. It divides the health care users among the haves and have-nots. Health care costs are a barrier to access to health care. Indeed, financial accessibility is one of the most important determinants of access to health care (Peters et al., 2008). It is most directly associated with the dimensions of poverty. The exclusion of users from health care or high-quality health care on the grounds of affordability amounts to social and economic exclusion.

Financial accessibility takes into account the Gross Domestic Product within the study area, direct costs such as treatment costs, drug and medication costs and indirect costs such as transportation costs, opportunity costs of time of both the patient and those accompanying him or her and expenses on food and lodging. Peters et al (2008: 6) define financial accessibility as 'the relationship between the price of services (in part affected by their costs) and the willingness and ability of users to pay for those services, as well as be protected from the economic consequences of health costs'. 


\subsection{Acceptability of healthcare}

Acceptability of health care takes into account the universally accepted legal, ethical, social, cultural and other norms and standards. According to Peters et al (2008) acceptability measures the responsiveness of health services to the social and cultural expectations of individual users and communities. The Declaration of Alma Ata points out that primary health care must be in line with prevailing cultural norms (Peters et al., 2008). It must also take into account patients' perception of quality, price and other dimensions of access. Staff attitudes, cultural acceptability and quality of health care are important parts of heath care access (SAHRC, 2009).

\subsection{The barriers to health care access}

According to Jacobs et al (2008) -

Demand-side determinants are factors influencing the ability to use health services at individuals, households or the community level, while supply-side determinants are aspects inherent to the health system that hinder service uptake by individuals, households or the community.

According to Jacobs et al (2011) barriers to health care access can stem from the demand side and/or the supply side. Both demand-side barriers and supply-side barriers have to be addressed concurrently (O'Donnell, 2007) by means of interventions (Ensor \& Cooper, 2004).

\section{Materials and Methods}

The study employs a quantitative research approach (De Vos et al, 2005; Creswell, 1994; Neuman, 2000) and was undertaken at Ratshaatsha Community Health Centre $(\mathrm{RCHC})$ which is situated in the Blouberg Municipality. The researcher randomly sampled selected 30 participants (Welman, Kruger and Mitchell, 2005). All protocols associated with sound scientific research such as voluntary participation, confidentiality, privacy and no harm to participants were observed.

\section{Findings}

\subsection{Demographic profile of the respondents}

Out of thirty respondents, eighteen were male $(60 \%)$ and twelve were female $(40 \%)$. Seven respondents (23\%) fall within the age category of 20-45, ten respondents (33\%) fall within the age category 46-60 and thirteen respondents (43\%) fall within the age category 61 and above. Twelve respondents (40\%) earn social pension provided by government. Nine respondents (30\%) have miscellaneous sources of income such as subsistence farming and business. Six respondents (20\%) are state employees. Three respondents (10\%) have no income. Eighteen respondents (60\%) earn between 0 and R1200 per month. One respondent (3\%) earns between R1201 and R1500 per month, while 3 respondents (10\%) earn between R1501 and R2000. Eight respondents (27\%) earn more than R2000.

\subsection{Geographic accessibility (distance and means of transport)}

Ten respondents (33\%) reside within $10 \mathrm{~km}$ radius, twelve $(40 \%)$ reside within $20 \mathrm{~km}$ radius and eight $(27 \%)$ reside within $30 \mathrm{~km}$ radius. Eleven respondents (37\%) indicated that they use taxis to visit the $\mathrm{RCHC}$. Five respondents $(7 \%)$ indicated that they use bus transport. Two respondents (7\%) indicated that they use own or family-owned cars. Six respondents (20\%) indicated that they use other means of transport such as bicycles and donkey carts. Six respondents (20\%) said they walk.

\subsection{Waiting time}

Seventeen respondents (57\%) indicated that when they visited the RCHC they were attended to within 60 minutes of their arrival. Eight respondents (27\%) indicated they waited for one to two hours (61-120 minutes). Four respondents (13\%) indicated that they waited for two to three hours (121 - 180 minutes). One respondent (3\%) indicated that he waited for over three hours (181 minutes and more). 


\subsection{Availability of medication}

Eleven respondents (37\%) said medication required for their personal conditions was always available. Seventeen respondents (57\%) said their medication was sometimes available. Two respondents (7\%) said their medication was seldom available.

\subsection{Service hours and appointments}

Two respondents (7\%) said that they arrived at $07 \mathrm{~h} 00$ and the RCHC attended to them at $07 \mathrm{~h} 00$. Sixteen respondents (53\%) said, although they arrived at $07 \mathrm{~h} 00$ or earlier, the RCHC started to provide service at $07 \mathrm{~h} 30$. Ten respondents $((33 \%))$ said, although they arrived at 07h00 or earlier, the RCHC started to provide service at $08 \mathrm{~h} 00$. One respondent (3\%) said, although he arrived at $07 \mathrm{h00}$ or earlier, the RCHC started to provide service at $08 \mathrm{~h} 30$. One respondent (3\%) said, although he arrived at $07 \mathrm{~h} 00$ or earlier, the RCHC started to provide service at $09 \mathrm{~h} 00$. As things stand $07 \mathrm{~h} 30$ and 08h00 appear to be the favoured service times.

Twenty seven respondents (90\%) said when they visited the RCHC, without appointment and they were helped. Three respondents (10\%) said when they visited the RCHC, without appointment, they were not helped but were given appointment for another day.

\subsection{Rating of health services}

Of the thirty (30) respondents, six respondents (20\%) said the health services at RCHC were good and fourteen respondents (47\%) said the services were average and ten the respondents (33\%) said the services were poor.

\subsection{Financial accessibility and choice of service}

According to respondents, $\mathrm{RCHC}$ provides free service. Nine respondents (30\%) said even if they had a choice between the RCHC and competing health care providers they would continue to use the health services at the RCHC. On the contrary, twenty one respondents (70\%) said if they had such a choice they would not continue to use the services at the $\mathrm{RCHC}$.

\subsection{Use of Alternative health services}

Twenty-nine respondents (97\%) said they use alternative health services more often. One respondent (3\%) said he often uses the services of alternative health services providers. No respondent said he or she seldom uses the services of alternative health services providers.

Thirteen respondents (43\%) said they use ZCC faith-healing services, while six respondents (20\%) said they use the services of St Engenas ZCC, four respondents (13\%) use the services of Apostolic Church. Five respondents (17\%) use the services of traditional African religion. Six respondents (6\%) use the services of other faiths.

\subsection{Health care access and barriers}

While all respondents (100\%) often receive services at the $\mathrm{RCHC}$, none of them said that he or she always have access to health services at $\mathrm{RCHC}$.

Four respondents $(13 \%)$ complained that distance makes it difficult to access health care at RCHC, five respondents (17\%) cited transport, four respondents (13\%) cited affordability, five respondents (17\%) cited staff attitude, six respondents (20\%) cited lack of drugs and six respondents (20\%) said they prefer alternative health services. However, there is a cross-section of the causes of lack of health care access.

\section{Discussion}

To address the question of whether there are there gaps between human rights in principle and human rights in practice, the study shows that there are gaps between human rights in principle and human rights in practice. The largest group of health care users does not enjoy the right to have access to health care. The following factors account for gaps between human rights in principle and human rights in practice: quality of health services; travelling distance and time; roads and 
transport; cost; staff attitude; scarce skills; lack of medicines and drugs; lack of medical equipment; waiting periods; and opening time (starting and closing times).

The study sought to uncover whether there are any violations of the rights of individuals to have access to health care services. The study revelas that the following factors account for the violations of the right to health care access at $\mathrm{RCHC}$ -

- Distance: The standard is that there must be at least a health facility within a $25 \mathrm{~km}$ radius. In the study, the target population resides generally within $30 \mathrm{~km}$ radius.

- Poverty: The target population is relatively poverty-stricken. Eighteen respondents (60\%) earn between 0 R1 200, 00 per month and 30\% of the respondents were not economically active and, therefore, earn no income. The majority of the population is poor. Poverty is a barrier to health care access.

- Waiting period: According to this study, $57 \%$ of the respondents indicated that they were attended to within 60 minutes of their arrival at the out-patient department. About a quarter indicated they waited for one to two hours (61 - 120 minutes), 4 respondents indicated that they waited for two to three hours (121 - 180 minutes) and 1 respondent (3\%) indicated that he waited for over three hours (181 minutes and more).

- Staff attitude contributes to the length of the waiting period. Seventeen per cent of the respondents said they did not have access to health care due to staff attitudes.

- Lack of skills, medicines, drugs and medical equipment: According to the study, the lack of equipment and medication contribute to the denial of health care access. In fact, $20 \%$ of the respondents said they did not have access to health services because of lack of medicines and drugs.

It can be concluded that the RCHC does not meet the standards set out in the General Comments No 14.

Why do some people in the study area still make use of alternative health care services? Almost all the respondents said they are religious. They either belong to organised faith (church) or traditional African religion. The undeclared reason is that they use the alternative health services because they are provided by their own churches or faiths. However, the majority of the respondents use both systems of health services, namely government public health services and alternative health services. The minority rely heavily on alternative health services. The minority of the respondents said they the cost of transport, user fees and other incidental expenses are prohibitive.

According to this study, $97 \%$ of the respondents said they use alternative health services more often. Only one respondent said he often uses the services of alternative health services. Forty three per cent of the respondents often use alternative health services said they use the services of ZCC, 20\% used the services of St Engenas ZCC, 13\% used the Apostolic Church. Seventeen per cent said they practise traditional African religion and use the religious services for health purposes while $7 \%$ said they use the services of other alternative health services providers.

The research also sought to understand what policy interventions are necessary to make health care services accessible. The state has enacted many legislative and other measures to undergird access to health care by all. For instance, the following measures have been enacted: The Constitution of the Republic of South Africa, 1996; National Health Act, 61 of 2003; Promotion of Equality and Prevention of Unfair Discrimination Act, 4 of 2000; Promotion of Administrative Justice Act, 3 of 2000; Promotion of Access to Information Act, 2 of 2000; Traditional Health Practitioner Act, 2004 (35 of 2004); Regulation 158/6832/1 February 1980; Department of Health Restructuring the National Health System for Universal Primary Health Care - Official Policy Document issued by the Department of Health (DOHPOLDOC)1996: 5; National Health Plan for South Africa (1994) and White Paper for the Transformation of the Health System of South Africa (1997.

\section{Towards a Model of Efficient Delivery of Health}

This article postulates the following model to inform both practice and policy:

- Government must adopt human rights-approach to health care delivery.

- The health care delivery must be people-centered and people-driven.

- Health care delivery must be provided in an integrated intergovernmental manner.

- Staff must undergo change management and people skills training.

- Procurement and distribution of medication should be improved in accordance with the international best practices.

- Government should recognise the alternative health care providers as a fact of life.

- Government should co-ordinate primary health care services in collaboration with churches and traditional healers. 
- Priests and healers should be trained in patient management, in particular management of communicable diseases.

- There must be cross-referral of patients.

- Government should implement existing health legislative and related measures.

- Government should improve community participation in future health care policy development and implementation.

- Government should co-ordinate the development of health care management guidelines for health care providers.

- The Monitoring and Evaluation Unit must intensify its activities, site visits and reporting.

- Government must integrate health care indicators into Integrated Development Plans.

- There must be a community clinic within an $8 \mathrm{~km}$ radius of a community.

- The Government should develop and implement a mechanism that enforces compliance with international best practices as well as norms and standards.

\section{Conclusion}

The state has taken legislative and other measures to protect, promote and fulfill the right of the people to health care services. Basically, integrated development approach to health provisioning is the most appropriate approach to improve access to health care at Ratshaatsha Community Health Care and everywhere else. Government must strengthen and consolidate vertical and horizontal intergovernmental fora for purposes of optimising co-ordination and improvement of the quality of public services. The integrated development plans and local economic development must take into account the related objectives and roles of each sphere of government. The principle of community participation must be given regard as one of the fundamentals for sustainable community development.

\section{References}

Cheadle, M H, Davis, DM \& Haysom, NRL (2002) South African Constitutional Law: The Bill of Rights, Butterworths, Durban Creswell, JW (1988) Qualitative inquiry and research design: choosing among five traditions, Sage: Thousands Oaks Currie, I and De Waal, J (2005) The Bill of Rights Handbook, Juta: Cape Town

Currin, G, Mathauer, L Xu K \& Evans, DB (2008) "Universal coverage of health services: tailoring its implementation" Bulletin of the World Health Organization 86: 857-63

De Vos, AS, Strydom, H, Fouche, CB, \& Delport, CSL (2005) Research at Grassroots - for Social Science and Human Service Professions, Van Schaik: Pretoria

Ensor, T \& Cooper, S (2004) "Overcoming barriers to health services access: Influencing the demand-side" Health Policy and Planning (19)(2):69-79

Fouche, CB \& Delport, CSL "In-depth review of literature " in De Vos, Strydom, Fouche and Delport (2005) Research at grass roots - for the social sciences and human service professions, Van Schaik: Pretoria

Jacobs, B, Por, IR, Bidgeli, M, Annear, PL, van Damme, W (2011) "Addressing access barriers to health services: an analytical framework for selecting appropriate interventions in low-income Asian countries" Health Policy and Planning (19)(2):69-79

Matsepe, SS (2004) The Appropriation of African Traditional Healing by the Zionist Churches: A Challenge to the Mission Churches in Gaborone "Botswana" (MTh. UNISA)

Mbiti, SJ (1969) African Religions and Philosophy, Heinemann Education Publishers

Mubangisi, J.C (2004) The Protection of Human Rights in South Africa - A Legal and Practical Guide, Juta, Cape Town

Nadasen, S (2000) Public Health Law in South Africa, Butterworths, Durban

Neuman, WL (2000) Social research methods: qualitative and quantitative approaches, Allyn \& Bacon, Boston

O'Donnell, O (2007) "Access to health care in developing countries: breaking down demand-side barriers" Cadernos de Saude Publica $232820-34$

Oliver, A \& Mossialos, E (2004) "Equity of access to health care: outlining foundations for action" Journal of Epidemology and Community Health 58:655-658

Peters, DH, Garg, A, Bloom, G, Walker, DG, Brieger, WR \& Rahman, MH (2008) "Poverty and access to health care in developing countries" Annals of the New York Academy of Science vol 1136 161-71

Olowu, D (2009) An integrative rights-based approach to human development in Africa, Pretoria University Law Press: Pretoria

Todaro, MP \& Smith, SC (2009) Economic Development, Addison Wesley (an imprint of Pearson Education, England): London

Welman, Kruger and Michell (2005) Research Methodology, Oxford University Press: South Africa

Yegidis, BL \& Weinbach, RW (1996) Research methods for social workers, Allyn \& Bacon 
Statutes

The Constitution of the Republic of South Africa, 1996

National Health Act, 61 of 2003

Promotion of Equality and Prevention of Unfair Discrimination Act, 4 of 2000.

Promotion of Administrative Justice Act, 3 of 2000

Regulation 158/6832/1 February 1980

National Plans, Policies and Programs

Reconstruction and Development Program (1994)

National Health Plan for South Africa (1994)

SAHRC Public Inquiry: Access to Health Care Services (2009)

White Paper for the Transformation of the Health System of South Africa (1997)

International human rights instruments

UNDP Human Rights Report (2000): Human Rights and Human Development. http:/hdr.undp.org/reports/global/2000/en UNDP Indicators for Human Rights-based Approaches to Development in UNDP Programming: Users' Guide (2006)

Vienna Declaration and Plan of Action

Continental Instruments

African Charter of Human and Peoples' Rights

Court decisions

AZAPO v President of the RSA 19968 BCLR 1015 (CC)

B v Minister of Correctional Services 19976 BCLR 789 (C)

Government of the Republic of South Africa v Grootboom and Others 2000 (11) BCLR 1169 (CC)

Soobramoney v Minister of Health, KwaZulu-Natal 1997 (12) BCLR 1696 (CC) 